\title{
Skeletal muscle metastasis from malignant melanoma: a case report and review of the literature
}

\author{
Yujin Zhu ${ }^{1,2}$, Sathiyamoorthy Selvarajan ${ }^{3}$, Kesavan Sittampalam ${ }^{3}$, Richard Quek ${ }^{4}$, Mohamad \\ Farid $^{4}$, Melissa Ching Ching Teo ${ }^{1,2}$ \\ 1. Department of Surgical Oncology, National Cancer Center Singapore, Singapore. 2. Department of General Surgery, \\ Singapore General Hospital, Singapore. 3. Department of Pathology, Singapore General Hospital, Singapore. \\ 4. Department of Medical Oncology, National Cancer Center Singapore, Singapore.
}

Correspondence: Melissa Ching Ching Teo. Address: Department of Surgical Oncology, National Cancer Center Singapore, 11 Hospital Drive, Singapore. E-mail: melteo1@gmail.com

Received: December 16, 2014 Accepted: February 5, 2015

Online Published: February 28, 2015

DOI : $10.5430 /$ crcp.v2n3p1

URL: http://dx.doi.org/10.5430/crcp.v2n3p1

\begin{abstract}
Malignant melanoma can spread to any organ. The most common sites of metastasis are skin, subcutaneous tissue and lymph nodes, followed by lung, liver and brain. Skeletal muscle metastases from melanoma are rare and only reported sporadically in literature. We report a case of a 31 year old male with multiple intramuscular metastases from malignant melanoma.
\end{abstract}

\section{Key words}

Melanoma, Skeletal muscle metastasis

\section{I ntroduction}

Malignant melanoma is characterized by extreme variation in its biologic behavior which can spread to any organ. The most common sites of metastasis are regional skin, subcutaneous tissue and lymph nodes, followed by lungs, liver, brain, bone and intestine ${ }^{[1]}$. Different melanoma subtypes may show distinct metastatic preference. Superficially spreading and nodular melanomas spread to the brain more frequently, whereas acral-lentiginous and mucosal melanomas have a tendency to affect the bone ${ }^{[2]}$. However, distant skeletal muscle metastasis is a rare event and is only reported sporadically in literature ${ }^{[3-6]}$. We present a rare case of a 31 year old male with multiple intramuscular metastases from a malignant melanoma.

\section{Case presentation}

A 31-year-old male presented with a right shoulder skin nodule with bleeding, which started as a simple mole that became raised and bigger over two years. Physical examination revealed an irregular, variegated (black and red), polypoid nodule of $30 \mathrm{~mm}$ diameter on the right anterior deltoid, with rough edge and central ulceration (see Figure 1). A total excision biopsy of the lesion was performed and the histology showed T4b nodular melanoma with Breslow thickness of $10 \mathrm{~mm}$ and Clarkes level III. There was no microsatellite and its deep and lateral margins were free of tumour involvement (see Figure 2a). Initial staging workups including bone scan, CT neck and thorax were all negative. A wide excision was Published by Sciedu Press 
subsequently carried out with $2 \mathrm{~cm}$ circumferential radius round the excision biopsy scar, down to deltoid muscle, along with sentinel lymph node biopsy from the right axilla, which was located by injection of sulphur colloid labelled with Technetium-99m peri-tumorally at the right shoulder, and a deltopectoral flap to cover the deltoid defect. There was no residual melanoma on wide excision but one out of three sentinel lymph nodes were positive for melanocytes with maximum dimension of $0.06 \mathrm{~mm}$. In view of AJCC stage IIIB disease (T4bN1 aM0, American Joint Committee on Cancer stage 2009), the patient was counselled for a completion right axillary clearance but refused. No adjuvant treatment was given afterwards.

Figure 1. Nodular melanoma. A large $(30 \mathrm{~mm})$ irregular, variegated (black and red), polypoid nodule with rough edge and central ulceration arising on the right anterior deltoid of this 31-year-old male.
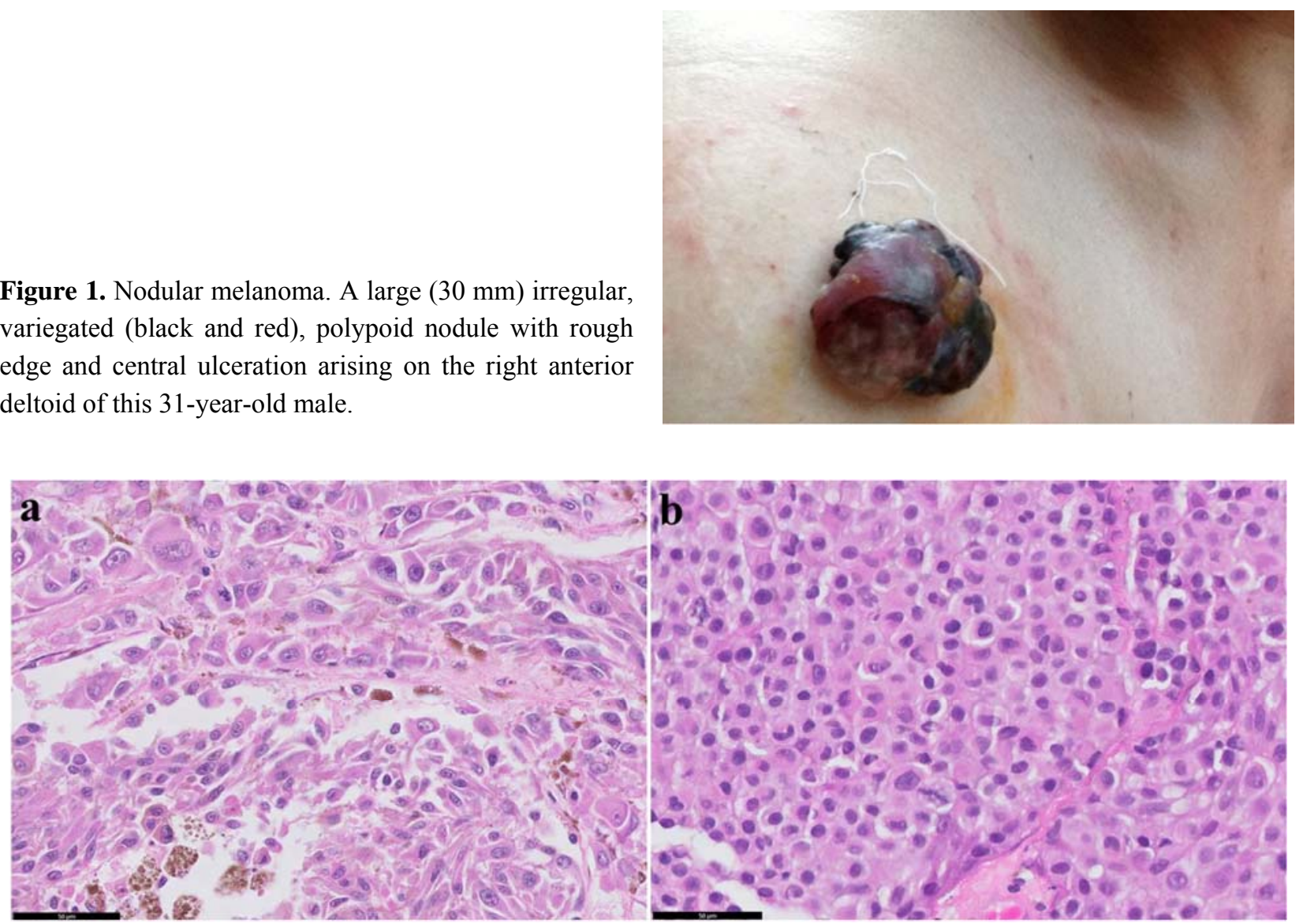

Figure 2. Microscopic findings of the primary shoulder mass (a) and the metastatic right thigh mass (b). Highly atypical melanocytes are seen with marked pleomorphism and scattered melanin pigments (Higher magnification), features in keeping with malignant melanoma.

Six months after the primary resection, he presented again with two gradually enlarging soft tissue masses. One was in the left calf causing pain and difficulty in ambulating, and the other one was painless in the right thigh. This was associated with a loss of 10 pounds over one month. Examination revealed two ill-defined non-tender masses over the left posterior calf and right anterolateral thigh, with normal overlying skin. An F-18 PET/CT scan was performed and showed no local recurrence in the primary site at the right shoulder nor at the right axilla, nor lung, liver or brain metastases. However, intense FDG-avid masses were present in the left calf gastrocnemius measuring $8.5 \mathrm{~cm} \times 6.2 \mathrm{~cm} \times 4.8 \mathrm{~cm}$ (see Figure $3 \mathrm{~d}$ ) and the right thigh vastus lateralis muscle measuring $5.0 \mathrm{~cm} \times 4.2 \mathrm{~cm} \times 2.6 \mathrm{~cm}$ (see Figure $4 \mathrm{~d}$ ), with appearances that were compatible with melanoma metastases. Mildly FDG-avid nodes were noted at the left obturator, left external iliac, left inguinal and left common femoral regions, suspicious for nodal involvement. An MRI scan was also performed and showed two enhancing intramuscular masses in the medial head of left gastrocnemius (see Figure 3a, 3b and 3c) and the right vastus lateralis (see Figure $4 \mathrm{a}, 4 \mathrm{~b}$ and $4 \mathrm{c}$ ), both $\mathrm{T} 1$-weighted isointense and nonspecific. Trocar biopsy of the right thigh was hence performed and histology showed features consistent with a metastatic melanoma (see Figure 2b). 
a

Figure 3. A well-defined mass lesion with T1 iso-intensity (a. axial T1 weighted image) and T2 hyperintensity (b. axial T2 weighted image) is noted in the left gastrocnemius muscle. There is enhancement after administration of gadolinium (c. axial contrast enhanced T1 weighted fatsuppressed image) and intense FDG uptake on the fused PET/CT (d. axial fused PET/CT image).

Figure 4. Another intra-muscular lesion is seen in the right vastus lateralis muscle with similar signal features as described in Figure 3. a. axial T1 weighted image, b. axial T2 weighted image, c. axial contrast enhanced $\mathrm{T} 1$ weighted image with fat-suppression, d. axial fused PET/CT image.
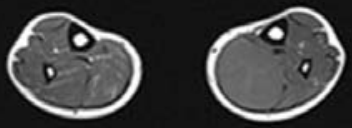

b
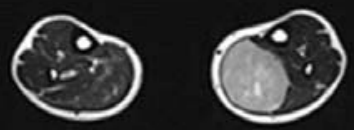

d
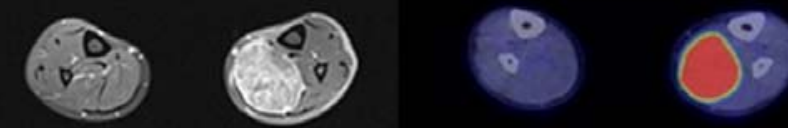

$\mathbf{a}$
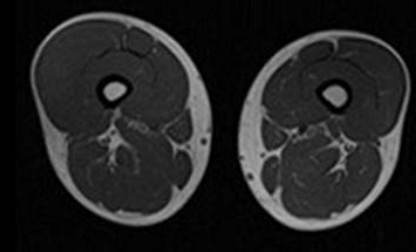

c

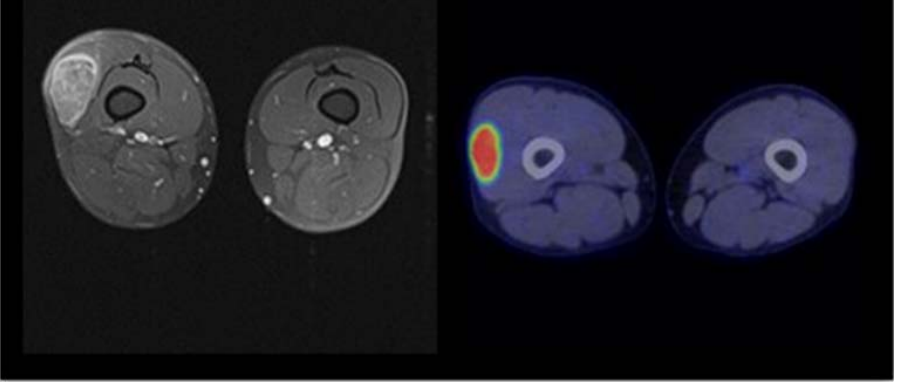

Furthermore, activating BRAF V600 mutation was detected in his genetic mutational analysis. However, patient declined commercial targeted and immunotherapy drugs due to financial stress, and chose to get recruited in the ongoing COLUMBUS trail, which is a phase III randomized, multicenter study, comparing LGX818 plus MEK162, LGX818 monotherapy versus vemurafenib in metastatic BRAF mutant melanoma ${ }^{[7]}$.

\section{Discussion}

Melanoma accounts for less than $2 \%$ of all skin cancer cases, but will cause approximately $74.8 \%$ of skin cancer mortality in the US in $2014{ }^{[8]}$. It is highly curable disease if detected in the early stage, with an overall 5 -year survival rate of $98 \%$ in localized diseases ${ }^{[8]}$. However, it's more likely to spread compared to other non-melanoma skin cancers, in a highly variable behavior pattern influenced by histologic subtypes ${ }^{[2]}$. And 5 -year survival will decline to $62 \%$ and $16 \%$ for regional (AJCC stage III) and distant metastatic disease (AJCC stage IV), respectively ${ }^{[8]}$. 
We reported a case of stage III melanoma that experienced early distant recurrence in the skeletal muscle with only six-month recurrence-free survival (RFS) after primary resection. Notably, his tumour harbors BRAF mutation, which is the most common oncogenic mutation in melanoma and frequently seen in nodular and superficial spreading melanoma ${ }^{[9]}$. It is associated with male gender, young age, trunk localization and intermittent sun exposure ${ }^{[9]}$. Although not conclusive, it was suggested to be linked with rapid progression, poor RFS and short disease-specific survival (DSS) in several independent post-resection stage III melanoma data sets ${ }^{[10-12]}$.

Skeletal muscle metastasis is rare in clinical setting and normally occurs as a late event in the progression of disease. The commonly reported primary malignancies that may metastasize to the skeletal muscle are lung cancer, renal cell carcinoma and gastrointestinal tumours and genital tumours, but rarely melanoma ${ }^{[13-22]}$. The best epidemiological evidence for skeletal muscle metastasis reported to date was from an 8-year retrospective review of Surov et al. They reported an incidence of $1.2 \%$ out of 5,170 patients that presented with metastatic solid malignancies, and most of them (91.8\%) already had widespread metastases when the distal skeletal muscle was found to be invaded, hence it's uncommon to see isolated intramuscular metastases without spreading to other distant organs as in our case. Notably, among all metastatic melanoma cases, only $3.6 \%$ of them had distant skeletal muscle involvement ${ }^{[21]}$. However, thorough postmortem studies yielded a higher prevalence of skeletal muscle metastases in all forms of metastatic neoplasms, ranging around $16 \%-17.5 \%$, without data specific for melanoma ${ }^{[23,24]}$. These findings imply that metastases in muscle may be not uncommon but it's rarely clinically apparent ${ }^{[25]}$. It might be due to only a fraction of patients are symptomatic, or most of them already have rampant diseases and rarely survive long enough to lead to clinical detection ${ }^{[23]}$.

Skeletal muscle is resistant to both primary and metastatic carcinoma. Several factors have been postulated to explain this phenomenon, including biomechanical damage to the cancer cell in the microvasculature of skeletal muscles ${ }^{[26]}$, inhospitable muscle $\mathrm{pH}$, extremely variable blood flow, muscles' ability to remove lactic acid, which induces angiogenesis in other tissues if accumulated ${ }^{[27]}$, and the active lymphocytes and natural killer cells in skeletal muscle, which play a major role in the inhibition of tumour metastases ${ }^{[28]}$.

The common clinical scenario in which skeletal muscle metastasis is detected is the presenting symptom of a painful mass (usually more than $5 \mathrm{~cm}$ in diameter) ${ }^{[13-22]}$. This may be an important clue to suggest metastasis rather than a primary sarcoma of soft tissue, which is more commonly seen but typically present as painless soft tissue masses ${ }^{[14,20]}$. Making a distinction between the two is important as the treatment and prognosis are markedly different.

Various imaging modalities have been used to identify skeletal muscle metastases. On CT scanning, the most common findings are focal intramuscular masses with homogenous contrast enhancement, followed by rim enhancement with central hypoattenuation ${ }^{[21]}$. When combined with Positron Emission Tomography, FDG PET/CT is more sensitive for the diagnosis of muscle metastases and more accurate to stage advanced malignancy especially when nodal disease is present ${ }^{[29]}$. MRI is still the gold standard for imaging muscle disease and is indispensable in diagnosing soft tissue malignancy. The lesions are usually of low signal intensity on T1 and high signal intensity on T2 weighted images and enhancement with gadolinium ${ }^{[13]}$. These findings are not pathognomonic for skeletal muscle metastases and differential diagnosis should include sarcoma and abscess ${ }^{[30]}$. For melanotic melanoma in particular, MRI can be diagnostic if specific features are present. Typically, metastatic melanotic melanomas demonstrate high intensity on T1 and low intensity on T2-weighted images, with enhancement in a peripheral rim pattern or a diffusely heterogeneous pattern ${ }^{[4]}$. These features are due to the paramagnetic effect of stable free radicals present in melanin ${ }^{[31]}$. However, the MRI findings in this case were not diagnostic, which might be due to the poor differentiation of metastatic lesions and the lack of melanin (see Figure 2b). Since imaging modalities are not always specific to distinguish intramuscular metastases from sarcoma, a biopsy is always referred for an accurate diagnosis. Both fine needle aspiration biopsy and trocar biopsy are efficient for differentiation in most cases ${ }^{[16]}$.

The prognosis of patients with skeletal muscle metastases from melanoma is currently uncertain given that very few reports are present in the literature. The mortalities reported in the literature were usually within 10 months of 
diagnosis ${ }^{[5,14,32]}$. The poor prognosis could be associated with the fact that skeletal muscle metastases generally occur as a result of systemic dissemination and limited treatment options were available at that point.

Treatment of these patients will depend on clinical setting and the condition of patient, but primarily should be palliative and cause as little morbidity as possible. Options may include radiotherapy, palliative surgical excision, chemotherapy and sometime interferon- $\alpha$ if patient is fit and able to tolerate the toxicities. Pain due to skeletal muscle metastases can be effectively palliated by radiation therapy using a dose of $40 \mathrm{~Gy}-50 \mathrm{~Gy}{ }^{[13]}$. And surgical excision may be helpful in carefully selected patients such as those with painful isolated masses and following a long disease-free interval after appropriate treatment of the primary carcinoma. Recent research has shed some light on the treatment of stage IV melanoma after targeted inhibitors to BRAF V600, KIT and MEK mutations have been developed ${ }^{[33]}$. Currently FDA has approved a few of these drugs including vemurafenib, debrafenib and trametinib. Although the rapid emergence of resistance to single agent is still limiting the clinical utility, combined BRAF and MEK inhibitors are under clinical trials with some evidence of reduced toxicity and increased efficacy ${ }^{[33]}$. However, more evidences are required to evaluate the effects of newer targeted or immunotherapy drugs on skeletal muscle metastases from melanoma.

\section{Conclusion}

Skeletal muscle metastases from melanoma are rare, but they may be present more often than generally thought, and can go undiagnosed for a prolonged period. MRI and PET/CT are important imaging modalities for diagnosis and staging. However, golden standard diagnosis is still biopsy in view of its similarity to sarcoma. The prognosis is poor as the disease is usually very advanced upon diagnosis. Treatment is primarily palliative. Newer targeted or immunotherapy drugs may improve survival but more evidence is required from clinical trials.

\section{References}

[1] Patel JK, Didolkar MS, Pickren JW, et al. Metastatic pattern of malignant melanoma. A study of 216 autopsy cases. American journal of surgery. 1978; 135(6): 807-10. Epub 1978/06/01. PMid: 665907.

[2] Schoenewolf NL, Belloni B, Simcock M, et al. Clinical implications of distinct metastasizing preferences of different melanoma subtypes. European journal of dermatology: EJD. 2014; 24(2): 236-41. Epub 2014/04/12. PMid: 24721680. http://dx.doi.org/10.1684/ejd.2014.2292

[3] Mercer NS, Devaraj VS. Intramuscular metastatic melanoma with an unknown primary. Br J Plast Surg. 1990; 43(3): 367-8. Epub 1990/05/01. PMid: 2350647.

[4] Yoshioka H, Itai Y, Niitsu M, et al. Intramuscular metastasis from malignant melanoma: MR findings. Skeletal radiology. 1999; 28(12): 714-6. Epub 2000/02/01. PMid: 10653368.

[5] Viswanathan N, Khanna A. Skeletal muscle metastasis from malignant melanoma. Br J Plast Surg. 2005; 58(6): 855-8. Epub 2005/08/10. PMid: 16086994. http://dx.doi.org/10.1016/j.bjps.2004.12.001

[6] Oittinen HA, O'Shaughnessy M, Cullinane AB, et al. Malignant melanoma of the ciliary body presenting as extraocular metastasis in the temporalis muscle. J Clin Pathol. 2007; 60(7): 834-5. Epub 2007/06/05. PMid: 17545559. http://dx.doi.org/10.1136/jcp.2005.033613

[7] Study Comparing Combination of LGX818 Plus MEK162 and LGX818 Monotherapy Versus Vemurafenib in BRAF Mutant Melanoma (COLUMBUS) 2014 [cited 201423 August]. Available from: https://clinicaltrials.gov/ct2/show/NCT01909453?term=metastatic + BRAF + mutant + melanoma\&rank=3

[8] Society. AC. Cancer Facts \& Figures 2014 [cited 201423 August]. Available from: http://www.cancer.org/acs/groups/content/@research/documents/webcontent/acspc-042151.pdf

[9] Yaman B, Akalin T, Kandiloglu G. Clinicopathological Characteristics and Mutation Profiling in Primary Cutaneous Melanoma. The American Journal of dermatopathology. 2014. Epub 2014/10/31. PMid: 25357015. http://dx.doi.org/10.1097/DAD.0000000000000241

[10] Moreau S, Saiag P, Aegerter P, et al. Prognostic value of BRAF(V(6)(0)(0)) mutations in melanoma patients after resection of metastatic lymph nodes. Annals of surgical oncology. 2012; 19(13): 4314-21. Epub 2012/07/10. PMid: 22772867. http://dx.doi.org/10.1245/s10434-012-2457-5 
[11] Mann GJ, Pupo GM, Campain AE, et al. BRAF mutation, NRAS mutation, and the absence of an immune-related expressed gene profile predict poor outcome in patients with stage III melanoma. The Journal of investigative dermatology. 2013; 133(2): 509-17. Epub 2012/08/31. PMid: 22931913. http://dx.doi.org/10.1038/jid.2012.283

[12] Barbour AP, Tang YH, Armour N, et al. BRAF mutation status is an independent prognostic factor for resected stage IIIB and IIIC melanoma: implications for melanoma staging and adjuvant therapy. Eur J Cancer. 2014; 50(15): 2668-76. Epub 2014/07/30. PMid: 25070294. http://dx.doi.org/10.1016/j.ejca.2014.06.009

[13] Sudo A, Ogihara Y, Shiokawa Y, et al. Intramuscular metastasis of carcinoma. Clinical orthopaedics and related research. 1993; 296: 213-7. Epub 1993/11/01. PMid: 8222429.

[14] Damron TA, Heiner J. Distant soft tissue metastases: a series of 30 new patients and 91 cases from the literature. Annals of surgical oncology. 2000; 7(7): 526-34. Epub 2000/08/18. PMid: 10947022.

[15] Glockner JF, White LM, Sundaram M, et al. Unsuspected metastases presenting as solitary soft tissue lesions: a fourteen-year review. Skeletal radiology. 2000; 29(5): 270-4. Epub 2000/07/07. PMid: 10883446.

[16] Pretorius ES, Fishman EK. Helical CT of skeletal muscle metastases from primary carcinomas. AJR American journal of roentgenology. 2000; 174(2): 401-4. Epub 2000/02/05. PMid: 10658714. http://dx.doi.org/10.2214/ajr.174.2.1740401

[17] Kim CJ, Day S, Yeh KA. Metastatic soft tissue squamous cell carcinoma. The American surgeon. 2001; 67(2): 111-4. Epub 2001/03/13. PMid: 11243530.

[18] Tuoheti Y, Okada K, Osanai T, et al. Skeletal muscle metastases of carcinoma: a clinicopathological study of 12 cases. Jpn J Clin Oncol. 2004; 34(4): 210-4. Epub 2004/05/04. PMid: 15121758.

[19] Koike Y, Hatori M, Kokubun S. Skeletal muscle metastasis secondary to cancer--a report of seven cases. Upsala journal of medical sciences. 2005; 110(1): 75-83. Epub 2005/04/02. PMid: 15801688.

[20] Plaza JA, Perez-Montiel D, Mayerson J, et al. Metastases to soft tissue: a review of 118 cases over a 30-year period. Cancer. 2008; 112(1): 193-203. Epub 2007/11/28. PMid: 18040999. http://dx.doi.org/10.1002/cncr.23151

[21] Surov A, Hainz M, Holzhausen HJ, et al. Skeletal muscle metastases: primary tumours, prevalence, and radiological features. European radiology. 2010; 20(3): 649-58. Epub 2009/08/27. PMid: 19707767. http://dx.doi.org/10.1007/s00330-009-1577-1

[22] Molina-Garrido MJ, Guillen-Ponce C. Muscle metastasis of carcinoma. Clin Transl Oncol. 2011; 13(2): 98-101. Epub 2011/02/18. PMid: 21324797. http://dx.doi.org/10.1007/s12094-011-0625-x

[23] Pearson CM. Incidence and type of pathologic alterations observed in muscle in a routine autopsy survey. Neurology. 1959; 9: 757-66. Epub 1959/11/01. PMid: 14431247.

[24] Acinas Garcia O, Fernandez FA, et al. Metastasis of malignant neoplasms to skeletal muscle. Revista espanola de oncologia. 1984; 31(1): 57-67. Epub 1984/01/01. PMid: 6545428.

[25] Swash M, Schwartz MS. Tumours of striated muscle and related disorders. Biopsy Pathology of Muscle: Springer US; 1991: 180-91.

[26] Weiss L. Biomechanical destruction of cancer cells in skeletal muscle: a rate-regulator for hematogenous metastasis. Clinical \& experimental metastasis. 1989; 7(5): 483-91. Epub 1989/09/01. PMid: 2752602.

[27] Seely S. Possible reasons for the high resistance of muscle to cancer. Medical hypotheses. 1980; 6(2): 133-7. Epub 1980/02/01. PMid: 7393016.

[28] Kurek JB, Nouri S, Kannourakis G, et al. Leukemia inhibitory factor and interleukin-6 are produced by diseased and regenerating skeletal muscle. Muscle \& nerve. 1996; 19(10): 1291-301. Epub 1996/10/01. PMid: 8808655. http://dx.doi.org/10.1002/(SICI)1097-4598(199610)19:10\&lt;1291::AID-MUS6\&gt;3.0.CO;2-9

[29] Mansour AA, Kelley MC, Hatmaker AR, et al. Verification of musculoskeletal FDG-PET-CT findings performed for melanoma staging. Annals of surgical oncology. 2010; 17(4): 1144-51. Epub 2009/12/08. PMid: 19967460.

http://dx.doi.org/10.1245/s10434-009-0843-4

[30] Williams JB, Youngberg RA, Bui-Mansfield LT, et al. MR imaging of skeletal muscle metastases. AJR American journal of roentgenology. 1997; 168(2): 555-7. Epub 1997/02/01. PMid: 9016246. http://dx.doi.org/10.2214/ajr.168.2.9016246

[31] Gomori JM, Grossman RI, Shields JA, et al. Choroidal melanomas: correlation of NMR spectroscopy and MR imaging. Radiology. 1986; 158(2): 443-5. Epub 1986/02/01. PMid: 3941871. http://dx.doi.org/10.1148/radiology.158.2.3941871

[32] Herring CL Jr, Harrelson JM, Scully SP. Metastatic carcinoma to skeletal muscle. A report of 15 patients. Clinical orthopaedics and related research. 1998; 355: 272-81. Epub 1999/01/26. PMid: 9917613.

[33] Garbe C, Peris K, Hauschild A, et al. Diagnosis and treatment of melanoma. European consensus-based interdisciplinary guideline--Update 2012. Eur J Cancer. 2012; 48(15): 2375-90. Epub 2012/09/18. PMid: 22981501.

http://dx.doi.org/10.1016/j.ejca.2012.06.013 